\title{
CULTURA E LITERATURA LATINO-AMERICANAS NA FRANÇA $(1922-1923)^{*}$
}

\author{
Dilma Castelo Branco Diniz **
}

\begin{abstract}
Resumo: Este trabalho tem por objetivo mostrar a recepção e divulgação da cultura e da literatura latinoamericanas na França, realizadas através da Revue de l'Amérique Latine, nos anos de 1922 e 1923, com artigos sobre personalidades latino-americanas da politica, das artes e das letras. Noticias a respeito de livros, jornais e revistas da América Latina, bem como uma crônica sobre a vida dos "Américains" em Paris fazem parte constante dos numeros da revista. Em razão dos limites deste estudo, dou prioridade às notícias sobre o Brasil e os brasileiros.
\end{abstract}

A influência da cultura e da literatura francesas na América Latina é um fato incontestável. Sabe-se, entretanto, que a reprodução do outro entre os povos dependentes não é necessariamente cega, nem a faculdade de criticar é privilégio dos países hegemônicos. Existe, portanto, a necessidade de se investigar, de fato, o que significou para a arte latino-americana esse renovado contacto com a cultura européia, principalmente em certos períodos históricos mais significativos, como por

- Recebido para publicação em novembro de 2004.

" Professora da Faculdade de Letras/UFMG. 
exemplo o primeiro quartel do século XX - a época das chamadas vanguardas.

Pierre Rivas já considerou "Paris como a capital literária da América Latina" (RIVAS, 1991: 99). O prestígio de Paris era grande sobre as elites crioulas, pois, tanto na Espanha como em Portugal, havia uma corrente modernizadora que reivindicava, ela própria, o modelo francês; daí a tentação dessas jovens nações de beberem diretamente na fonte francesa. Como as "revoluções" nacionais se faziam contra a península ibérica, adotar a França significava construir uma nova filiação, adotiva, para a construção da identidade nacional. Segundo Pierre Rivas, forma-se um "triângulo edipiano" que inclui

"uma Espanha renegada (arcaica e castradora) e uma França reverenciada como luz, modernidade, liberação. Esse 'romance familiar' no coração da neurose latinoamericana é, contudo, o modelo simbólico da sua emergência e da sua diferenciação nacional. Ele autoriza a emancipação literária." (RIVAS, 1991: 101-102).

Nessa citação, o nome de Portugal deveria estar ao lado da Espanha, já que a relação que aí se estabelece é a mesma para os dois países ibéricos.

$A$ viagem às fontes evidencia também a diferença e a descoberta da alteridade. É no exílio e pelo exílio que o escritor latino-americano redescobre sua pátria, o desejo de assumi-la e ilustrá-la. Isso acontece com Oswald de Andrade, redescobrindo o Brasil em Paris, e também com Jorge Luis Borges, César Vallejo (SCHWARTZ, 1995: 43-44) e muitos outros.

A questão da influência francesa na América Latina já foi bem estudada. O que ainda não foi devidamente pesquisado foi o movimento contrário, ou seja, no "contrafluxo da hegemonia": a divulgação e recepção da cultura e literatura latino- 
americanas na França. E um marco importante dessa divulgação foi a Revue de l'Amérique Latine, revista mensal que circulou na França de 1922 a 1932, com artigos sobre personalidades latino-americanas da política, das artes e sobretudo das letras. Notícias sobre livros, jornais e revistas da América Latina, bem como uma crônica sobre a vida dos "Américains" em Paris fazem parte constante dos números da revista.

Meu comentário se restringe aos números que encontrei na Biblioteca do Museu Paulista, em São Paulo: vários exemplares de 1922 e 1923. Em razão dos limites deste trabalho, procuro priorizar as notícias sobre o Brasil e os brasileiros - mais significativas para nós.

O primeiro número da revista é o de janeiro de 1922, cujo sumário revela um caráter tradicional. Abre-se o volume com o artigo "La croisade des conquistadors", de Francisco García Calderón, cujo título sugere um elogio aos aventureiros espanhóis que partiram para a conquista do Novo Mundo. Há dois poemas: o primeiro, intitulado "Herédia", de Henri de Régnier, da Academia Francesa e outro, de Jules Supervielle, "Le Gaucho". Dois artigos se referem a dois grandes nomes das letras latinoamericanas: "Ruben Dario" e "M. Ruy Barbosa". Na crônica sobre as artes, há um artigo intitulado "Chez Dada et hors de Dada", sobre o pintor Francis Picabia e uma nota elogiosa sobre Vera Janacopulos, "la belle cantatrice brésilienne".

Uma notícia de particular interesse para nós brasileiros é a da morte de "Mme. La Comtesse d'Eu", a nossa querida Princesa Isabel. Como se sabe, a Princesa se casou com D. Luís Gastão de Orléans, o Conde d'Eu, neto do rei Luís Felipe de França, daí o seu título de Condessa. De um modo geral, os brasileiros desconhecem o que aconteceu à princesa, nos seus anos de exílio na Europa. O texto revela que sua morte se deu após trinta anos de exílio e sucedeu a inúmeros golpes da vida. 
Declara que, acima da grande figura que se apaga, britha entretanto um título magnífico: "Redentora". Comentou-se muito sobre a oportunidade de uma reforma que, abolindo a escravatura, devia derrubar a monarquia. Mas os seus próximos garantem que a princesa exilada nunca se arrependeu do seu ato como princesa Regente. Há apenas um mês, no salão íntimo do "Château d' Eu" onde Dona Isabel continuava a receber seus amigos, como um parente muito querido observava diante dela as conseqüências políticas da abolição, a Princesa respondeu: "Se fosse para recomeçar, eu recomeçaria". O referido parente continuou dizendo que a maioria dos escravos, atirados na vida livre, morreram do uso abusivo do álcool... e que três anos mais tarde restavam muito poucos!

Não houve resposta, mas um sorriso sublime havia descontraído os traços esgotados da Princesa que, com um gesto da mão, mostrava o céu. Alguns instantes mais tarde, o fôlego voltou: "Deus me terá dado razão", desabafou. Essa bondade que, com o tempo, havia se tornado mais espiritualizada, essa consciência integral que não quer ver o obstáculo, uma vez definido o dever, eis os traços essenciais da "Comtesse d'Eu", afirma o artigo.

Os últimos dias da Princesa foram calmos. Na véspera de sua morte, Isabel de Orléans e Bragança havia assistido à missa no pequeno oratório do "Château d'Eu", no mesmo lugar em que Joana d'Arc tinha ficado prisioneira - fato bem significativo para o leitor.

O artigo, que ocupa quase toda a página 72 , tem a assinatura de Al. M. - iniciais que não consegui identificar. Em seguida, surge uma nota declarando que o Brasil concedeu honras de chefe de estado aos despojos mortais da princesa e a bandeira permaneceu a meio mastro na embaixada. Além disso, foi decretado luto oficial no Brasil e foi solicitado à Câmara um crédito para se erigir um monumento à antiga regente. Dom 
Pedro, seu pai, já tem sua estátua em Petrópolis e o mausoléu do imperador está sendo executado: o mármore do túmulo virá da França e as figuras ornamentais serão entregues a um escultor brasileiro.

Nota-se porém, nesse primeiro número da Revue de lAmérique Latine, uma importante lacuna: não existe um editorial de lançamento. Em geral, toda publicação periódica, ao colocarse diante de seu público, procura manifestar os objetivos a que se propõe: diz a que vem, como pretende ser e, muitas vezes, procura justificar sua aparição. É preciso entretanto lembrar que a Revue é, na verdade, a continuação do Bulletin de l'Amérique Latine, uma publicação fundada em 1910, sob o patrocínio do "Groupement des Universités et des Grandes Écoles de France" para as relações com a América Latina.

Encontrei esse texto "inaugural" somente no número de janeiro de 1923, com o título significativo de "A nos lecteurs" (p. 1-2). O texto inicia-se assim:

"A l'aube de la seconde année de sa nouvelle existence, la Revue de l'Amérique Latine est heureuse d'adresser ses plus vifs remerciements à tous ses lecteurs et collaborateurs." (p. 1)

Depois de outros agradecimentos, a direção da revista afirma que pode encontrar uma prova do interesse que a revista despertou nas discussões e mesmo nos protestos que suscitaram certos artigos, certas crônicas ou simples notas. "Essas últimas manifestações", continua o texto, "nos permitem estabelecer princípios que, esperamos, esclareçam os leitores que porventura se encontrem inquietos quanto ao espírito que anima a Revue de l'Amérique Latine."

Depois de comentar algumas reclamações de leitores que acusaram a revista de ser ora favorável à extrema direita ora favorável à extrema esquerda, o texto esclarece: 
"Qu'il nous soit permis d'ajouter que la Revue de l'Amérique Latine n'est ni un organe de droite, ni un organe de gauche. Le domaine de la politique lui est interdit. Publiée en français à Paris, elle s'adresse au public de France et à celui du Nouveau Monde latin. Rien de ce qui intéresse la grandeur de l'Amérique latine ne lui est étranger, et elle n'a pas d'autre objet que de resserrer les liens qui unissent entre elles et avec la France, des républiques dont la culture est orientée dans une direction parallèle." (p. 2)

O elogio da ordem e da tradição latinas também aparece claro, assim como o empenho da revista em preservar esse patrimônio.

"La Revue de l'Amérique Latine reste persuadée qu'il existe une clarté latine, un ordre latin, qui n'ont rien à envier à d'autres traditions ni à d'autres formes d'idéalisme. Elle les défendra de son mieux; mais cette défense générale ne lui donne pas le droit de s'immiscer dans les divergences que pourraient présenter, malgré la communauté de leur origine, les vingt peuples frères auxquels elle s'adresse, et dont la fière indépendance ne supporterait pas une critique de leurs directions politiques particulières." (p. 2)

Fica, portanto, reiterado o caráter "apolítico" da revista: os editores querem se resguardar, certamente, de possíveis e futuras divergências políticas.

Merece destaque o número de setembro de 1922, todo ele dedicado ao Brasil, no Centenário de sua Independência.

O primeiro texto, "Lîlot de Paqueta", um poema de Paul Fort, datado de agosto de 1921, já nos insere na paisagem brasileira do Rio de Janeiro. Segue um artigo de Magalhães de Azeredo, intitulado "Des traits de la physionomie morale de l'empereur 
D. Pedro II" e, em seguida, "Un siècle d'histoire politique", de Louis Guillaine, que comenta a vida política brasileira, desde a independência com D. Pedro I.

Gustave Simon assina um artigo sobre "Victor Hugo e Pedro II" e E. Montarroyos, outro sobre a "Independência do Brasil". Robert Ricard trata de "Publicações relativas à descoberta do Brasil e à expedição de Pedro Álvares Cabral" e Demétrio de Toledo, Adido do Consulado Geral do Brasil em Paris, é responsável pelo artigo "Le Brésil de nos jours et l'Avenir du Brésil" (parte I, o final do artigo vem no número seguinte).

Verifica-se, em todos esses escritos, uma preocupação maior com o passado, sendo uma exceção o texto de Demétrio de Toledo, que enfoca o Brasil do presente e do futuro. Reforçando essa ligação com o passado, esse número da revista publica ainda "La mouche bleue", poema de Machado de Assis, traduzido por Philéas Lebesque. Machado é qualificado de "o mestre da ironia brasileira" (p. 64).

Contrastando um pouco com o caráter conservador dos números anteriores, o exemplar de outubro de 1922 cita a Revista do Brasil (1922, n. 79, p. 361-362), que publicou um artigo de Nina Rodrigues sobre "O problema da raça negra na América Portuguesa"; e o número seguinte traz uma nota de V. García Calderón sobre "La poésie des noirs en Amérique Latine". Esse mesmo número, de novembro de 1922, anuncia que a revista argentina Nuestra América, de Buenos Aires, editou também um número especial bastante espesso em homenagem ao Brasil e apresenta outro dado interessante: Gabriela Mistral assina um longo artigo sobre "Le paysage mexicain" (p. 193-197) e tem alguns poemas publicados, com tradução de Georges Pillement (p. 241-243).

$\mathrm{O}$ ano de 1923 parece trazer novos ares para a revista, que se abre para as novidades e também aos leitores. Já comentamos 
que o número de janeiro apresenta um "discurso inaugural". Além disso, na rubrica "Les lettres brésiliennes" surge um longo artigo de Manoel Gahisto (p. 64-70), intitulado "Les tendances nouvelles - quelques noms et quelques livres: Alberto Rangel, João Ribeiro, Amadeu Amaral e Monteiro Lobato.

Convém fazer aqui um breve parênteses. Para o brasileiro de hoje, falar de "tendances nouvelles" em janeiro de 1923 é remeter logicamente aos acontecimentos da "Semana de Arte Moderna", em São Paulo. Mas parece que, naquela época, as pessoas ainda não tinham uma idéia da extensão que tomaria o seu significado. A menção à "Semana de 22" só aparecerá na célebre conferência que Oswald de Andrade pronuncia na Sorbonne, em 11 de maio de 1923 e que será publicada em julho do mesmo ano na Revue de l'Amérique Latine. E é curioso observar que, mesmo na referida conferência, a "semana de arte moderna" aparece sempre grafada com letra minúscula. Esse fato se deve, provavelmente, à falta de uma perspectiva histórica do próprio Oswald, já que a conferência foi proferida, praticamente, um ano depois da Semana. Se um dos principais integrantes do movimento modernista não podia ainda avaliar a espantosa repercussão que assumiria a "Semana de 22", na História literária brasileira, como esperar que um crítico estrangeiro o fizesse?

Voltemos ao artigo de Manoel Gahisto. Para ilustrar as "novas tendências" da literatura brasileira, o autor cita o romance Inferno Verde, de Alberto Rangel e o volume de João Ribeiro, $A$ Lingua Nacional, que defende uma gramática brasileira diferente da dos portugueses, já que as diferenças regionais pedem um estilo e métodos próprios. Comenta, em seguida, a preocupação nacionalista de Monteiro Lobato, que reclama um estilo próprio e não a cópia em todas as artes, sobretudo nos artigos reunidos no volume Les idées de Jeca Tatu. Elogia também a atuação de Lobato à frente da Revista do Brasil, conduzindo-a ao sucesso 
e conquistando simpatias sinceras, além das fronteiras de seu país. Considera o autor de Urupês um observador arguto, além de um contista preciso e saboroso. Para Gahisto, Lobato é um escritor de mérito que procura se aproximar da realidade de nosso país, através de uma linguagem bem brasileira. Cita o livro Urupês e o estudo de Lobato sobre o Dialeto Caipira, de Amadeu Amaral. Insiste no fato de que o Brasil é múltiplo e apresenta uma grande variedade de tipos: o gaúcho, o vaqueiro, o seringueiro, etc. Afirma ainda que um estudo sério de nosso país incluiria, necessariamente, uma pesquisa profunda de todas essas variantes, dos seus aspectos exteriores às características psicológicas.

No mesmo exemplar de janeiro de 1923, na rubrica sobre a vida artística, existe uma nota intitulada: "Les Artistes Américains au Salon d'Automne" e entre os brasileiros foram citados José de Andrade, que apresentou, uma sala de jantar, na seção de móveis; e em escultura, M. Brecheret e Mlle. Adrienne Wolkowyski-Janacopulus (p. 71).

O número de abril de 1923 anuncia a inauguração na Sorbonne, em 19 de fevereiro de 1923, do "Cours d'Etudes Brésiliennes", sob a direção do Professor Le Gentil, acompanhado dos professores Martinenche e Georges Dumas. Esse curso nasceu sob os auspícios da Academia Brasileira e da iniciativa de Afrânio Peixoto (p. 375). A revista do mês de junho de 1923 anuncia duas conferências proferidas por dois brasileiros, no dia 11 de maio de 1923. A primeira, de Rangel de Castro, que falou na "Société de Géographie", sobre as descobertas feitas no interior brasileiro pelo general Rondon; e a segunda, de Oswald de Andrade, que falou no "amphithéâtre Turgot", da Sorbonne, cedido pelo Prof. Le Gentil. O texto completo da conferência de Oswald de Andrade, intitulado "L'effort intellectuel du Brésil contemporain", sai publicado no número de julho de 1923 e sua 
tradução foi publicada na Revista do Brasil, de dezembro do mesmo ano ${ }^{1}$. Nesse texto, Oswald de Andrade traça um amplo panorama da evolução da cultura brasileira, desde a colonização jesuítica até aquela data, insistindo na atuação dos intelectuais seus contemporâneos. Essa conferência mereceu ainda um "bom resumo" no jornal francês Le Figaro e nota no New York Herald (DINIZ, 2000: 221), segundo comentário do próprio autor.

Assim como Manoel Gahisto, Oswald de Andrade menciona João Ribeiro e Amadeu Amaral, explicando que faltava a eles "o jargão das grandes cidades brasileiras", onde começa a brotar, sobretudo em São Paulo, a literatura dos novos imigrantes.

Oswald de Andrade refere-se ainda a Monteiro Lobato:

"Faltava a eclosắo das realidades presentes, onde o fundo e a forma, matéria e sentimento e expressão pudessem dar ao Brasil de hoje a medida intelectual de sua mobilização industrial técnica e agrícola. Os ensaios do escritor Monteiro Lobato, em São Paulo, fizeram compreender afinal que o Brasil se encarregava dessa responsabilidade. O Sr. Lobato teve a audácia de sair do domínio puramente documental, em que se acantonavam Veiga Miranda, Albertino Moreira, Godofredo Rangel e Waldomiro Silveira, reagindo também contra o urbanismo que dava a visão histórica do polígrafo Elysio de Carvalho, a obra de Thomás Lopes e João do Rio, e a primeira fase poética de Guilherme de Almeida.

Lobato tinha um longo conhecimento do Brasil, tendo feito seus estudos em São Paulo, tornando-se fazendeiro em seguida. A obra de ficção, desejada por Machado de Assis, realizou-se com a criação do tipo do Jeca Tatu. Era o inseto inútil da terra magnífica que, para gozar um

\footnotetext{
${ }^{1}$ A tradução da conferência publicada na Revista do Brasil apresenta certas lacunas e modificações em relação ao texto original. Cf. DINIZ, 2000, p. 221.
} 
espetáculo e ter uma ocupação, queimava as matas." (ANDRADE, 1923, n. 96, p. 386) ${ }^{2}$

Para Oswald de Andrade, Lobato soube criar um tipo brasileiro que representava verdadeiramente a realidade de nosso país, um tipo que fugia do "domínio puramente documental" $e$ exótico do regionalismo caboclo vigente. Há nesse trecho uma alusão clara ao ensaio machadiano "Instinto de Nacionalidade". De fato, Lobato, ao criar o Jeca Tatu, expressou um "certo sentimento íntimo" que o tornou verdadeiramènte "homem do seu tempo e do seu país". (MACHADO DE ASSIS, 1962: 804)

Oswald conta ainda que Rui Barbosa aproveitou-se do símbolo lobatiano numa de suas grandes campanhas eleitorais: Jeca Tatu representava o "Brasil apático, sem idealismo são".

Mas o símbolo vingou-se, agiu na mente popular brasileira e o povo transformou-o num emblema do

"Brasil tenaz, cheio de resistências físicas e morais, fatalizado mas não fatalista, tendo adotado pelas circunstâncias das suas origens e do seu exílio, esta espécie de vocação para a infelicidade observado inconscientemente pelos romancistas. Lobato conveio que Jeca Tatu queimava as matas nativas para deixar ao imigrante novo a possibilidade de estender a 'onda verde' dos cafezais." (p. 387)

Dessa forma, Jeca Tatu adquiria prestígio e importância, revelando afinal um lado bom: "Ele era o precursor da riqueza americana, aberta a todas as tentativas das raças viris" (idem).

$O$ conferencista ainda afirma que a influência de Lobato aumentou: sem querer, Lobato se fez etnólogo e depois, esteta.

\footnotetext{
${ }^{2}$ As notas de página seguintes referem-se a essa tradução.
} 
No seu livro Onda Verde, em que estuda a plantação de inúmeros cafezais paulistas, Lobato explicita um programa para a geração literária da época. Oswald cita então palavras extraídas de Onda Verde: "A epopéia, diz ele, (Lobato), a tragédia e a comédia do café, eis os grandes temas... sentir e contar a história da onda verde que digere as matas virgens" (p.387). A esse respeito, Oswald garante que já se inicia nas obras poéticas, novelas e romances, uma verdadeira antólogia do café, em que se debate o problema das velhas aristocracias da terra em luta com a invasão dos imigrantes.

Cumpre notar que esse programa estético de Monteiro Lobato - escrever sobre o ciclo do café - será depois imitado pelos escritores nordestinos que vão escrever sobre os ciclos da cana-de-açúcar e do cacau, a partir de 1930, numa postura ideológica semelhante à do autor de Urupês.

Oswald salienta a independência de Monteiro Lobato, que pouco se importa com as indagações críticas de Suárez, de Jules Romain, de André Salmon, de Elie Faure, de Lothe, Cocteau, Gleizes, Henri Prunières e com as novas gerações de Portugal, da Itália e da Espanha. Comenta ainda que Lobato não tenta verificar se nosso indianismo era natural ao tempo de Chateaubriand e se, pela segunda vez, poderia tratar-se de uma coincidência de etapas entre a nossa literatura e a européia. Sublinha entretanto que, seja como for, ele põe em foco aspectos inéditos da vida americana. O lado documental é o que o apaixona e ele inicia um retorno ao regionalismo, contrabalançado apenas pela imaginação de Deabreu e pela verve de Leo Vaz.

Menciona ainda Mário de Andrade e sua poesia livre, Manuel Bandeira, Menotti del Picchia e Ronald de Carvalho. Explica também que a crítica do país (Tristão de Athayde, Nestor Victor, etc.) acolhe com simpatia as primeiras obras do movimento, que ganha rapidamente a adesão de numerosos jovens. Comenta o 
teatro e a escultura, citando a obra de Victor Brécheret. Ao tratar da pintura moderna, afirma que os novos artistas começaram a reação contra os "museus da Europa", adotando os procedimentos modernos oriundos do cubismo. E declara: "O cubismo foi um protesto contra a arte imitadora dos museus" (p.389). Entre esses novos pintores, cita Di Cavalcanti, Annita Malfatti, Zina Aita, Rego Monteiro, Tarsila do Amaral e Yan de Almeida Prado, que lançam as bases de uma pintura realmente brasileira e atual.

Oswald de Andrade trata ainda da música brasileira contemporânea. Afirma que a nossa música, embora tenha sofrido a imitação européia, não está no canto melódico italiano; ela vive no urucungo do negro, na vivacidade rítmica do índio e na nostalgia do fado português. E conclui dizendo: "O Brasil, sob um céu deísta, toma consciência do seu futuro" (p. 389). A palavra "deísta" indica, com a liberdade religiosa, que o espírito brasileiro contemporâneo se libertava, finalmente, da escolástica jesuítica colonial.

Essa conferência de Oswald de Andrade constitui o texto mais importante sobre a literatura e a cultura brasileiras, veiculado pela Revue de l'Amérique Latine, nos anos de 1922 e 1923. Seu valor se deve não só à amplitude do panorama esboçado e à profundidade de sua reflexão, como também à sua contemporaneidade.

Acredito que essas notas, embora incipientes e fragmentárias, já que são fruto de pesquisa inicial sobre a Revue de lAmérique Latine, possam dar uma idéia da importância desse periódico, na divulgação da cultura e da literatura brasileiras e latino-americanas, na França dos anos 1922 e 1923. Um estudo mais aprofundado da revista poderá trazer novas luzes sobre a relação França-Brasil e apontar caminhos relevantes no âmbito da literatura comparada. 
Résumé: Ce travail a pour but montrer la réception et la divulgation de la culture et de la littérature latino. américaines en France, réalisées à travers la Revue de l'Amérique Latine, dans les années 1922 et 1923, avec des articles concernant quelques personnalités latino-américaines de la politique, des arts et des lettres. Des nouvelles de livres, de journaux et de revues de l'Amérique Latine, et aussi une cbronique sur la vie des Américains à Paris sont publiés regulièrement dans les numéros de la revue. En raison des limites de cette étude, jaborde, en priorité, les nouvelles sur le Brésil et les Brésiliens.

\section{Referências bibliográficas}

ANDRADE, Oswald de. O esforço intelectual do Brasil contemporâneo. Revista do Brasil, n. 96, p. 386, dez. 1923.

DINIZ, Dilma Castelo Branco. Três cartas inéditas de Oswald de Andrade a Monteiro Lobato. In: GALVÃO, Walnice N.; GOTLIB, Nádia Battella (Org.). Prezado Senbor, Prezada Senbora: estudos sobre cartas. São Paulo: Companhia das Letras, 2000. p. 221.

MACHADO DE ASSIS, J. M. Notícias da atual Literatura Brasileira. In: Obra completa. v. II. Organizada por Afrânio Coutinho. Rio de Janeiro: Ed. José Aguilar, 1962. p. 804.

Revista do Brasil, n. 79, de julho de 1922, p. 361-362.

RIVAS, Pierre. Paris como a capital literária da América Latina. In: CHIAPPINI, Lígia e AGUIAR, Flavio Wolf de (Org.). Literatura e História na América Latina. São Paulo: EDUSP, 1991. p. 99.

SCHWARTZ, Jorge. Vanguardas latino-americanas. Polêmicas, manifestos e textos críticos. São Paulo: EDUSP, Iluminuras, FAPESP, 1995. p. 43-44. 